\title{
Gametogenesis in Threatened Mystus cavasius from 'Haor' Basin in the North- Eastern Bangladesh
}

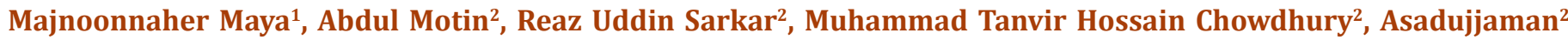 \\ and Harunur Rashid ${ }^{1 *}$
}

${ }^{1}$ Department of Fisheries Management, Bangladesh Agricultural University, Bangladesh

${ }^{2}$ Department of Fisheries, Ministry of Fisheries and Livestock, Bangladesh

*Corresponding author: Harunur Rashid, Department of Fisheries Management, Bangladesh Agricultural University, Mymensingh-2202, Bangladesh

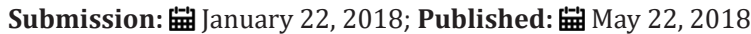

\begin{abstract}
This study was conducted to observe the month-wise gonado-somatic index (GSI), identify breeding frequency, peak breeding season, process of gametogenesis and furnish guideline for conservation of a threatened fish species Mystus cavasius from the 'Haor' region in the Northeaster Bangladesh. The GSI of male M. cavasius was found highest (3.41) in early July and the lowest (0.05) in late September and for female it was highest (24.54) in late July and the lowest (0.19) in October. Presence of oogonia (OG), perinucleolar oocyte (PNO), previtellogenic oocyte (PVO), yolk vesicle (YV), yolk granule (YG), premature (PM) and mature (M) stages of oocytes observed in the histological study of ovary. The mature stages of oocytes (PM and M) were observed in early July to August samples and developed oocytes (OG, PVO and PNO) were observed in the September samples. It was found that oocytes did not develop synchronously. Spermatocytes (SPC), spermatids (SPT) and spermatozoa (SPZ) testicular germ cells were identified during July to October samples. High proportions of mature germ cells (SPT and SPZ) were observed during July to August samples of testes when SPC was in low proportions. In post-monsoon samples (September to October), high abundance of early stage germ cells (mainly SPC) were observed indicating spent phase of testes. The study indicated that the peak breeding season of M. Cavasiusto be July owing to occurrence of high GSI and appearance of mature oocytes and mature testicular germ cells in this month. This study provides the first detailed information about oogenesis and spermatogenesis of $M$. cavasius from the Mymensingh Region of Bangladesh.
\end{abstract}

Keywords: Mystus cavasius; Gametogenesis; Gonadosomatic index; Haor basin

\section{Introduction}

Knowledge of reproductive biology of a fish is essential for evaluating the commercial potentialities of its stock, life history, culture practice and actual management of its fishery [1]. Reproductive potential of a population is one of the basic existences to designate the individuals of that population in respect to their gonadal conditions [2]. Knowledge of gonadal development and the spawning season of a species allow subsequent studies on spawning frequency of its population, which is important for its management [3]. Mystus cavasius is a freshwater catfish in Indian subcontinent and also very popular food fish [4]. It locally known as 'Tengra or Kabasi tengra or Gulsha tengra' is found in Bangladesh, India, Nepal, Pakistan, Sri Lanka, Myanmar, Thailand, Indo-China, Malaysia, East Indies, Syria and West Africa [5].

There are 54 threatened fish species of fresh water bodies, now 12 are critically endangered, 28 are endangered and 14 are vulnerable situation [5]. According to Red list of IUCN M. cavasius is a vulnerable species. Gametogenesis is the process for the formation of gametes, ovum or sperm in the gonad through which species conservation; management is possible specially threatened species. The oocytes and spermatocytes are both gametocytes and ova \& spermatids are complete gametes. For example, in M. vittatus, oocytes maturation stages were classified into nine stages, viz., chromatin nucleus, early perinucleolus, late perinucleolus, yolk vesicle, early yolk granule stage, late yolk granule stage, migratory nucleus, premature and mature stage [6]. The mature and premature stages are generally observed as the most advanced stage of ovary. The testicular germ cell stages observed were spermatocytes, spermatids, spermatozoa. It is most important to know the number of eggs, fry and young that could be produced from an individual brood fish for the purpose of better management and production.

Gonado-somatic index (GSI) also determines the state of maturity and onset of spawning season used to follow the 
reproductive cycle of a species over the year at monthly or less intervals. This index, which assumes that an ovary increases in size with increasing development, compared with the total mass of the fish. To determine the breeding season, it is necessary to know the condition of the female, its ovaries and eggs size [7]. However, till date there is no report on the reproductive biology, spawning parameters and life history states of M. cavasius of Sylhet 'haor' basin in the Northereaster Bangladesh. The objective of this study was to observe the GSI, breeding frequency of male and female through histological process and to determine the peak breeding season combining GSI and gonad histology data and finally to identify the process of gametogenesis in ovary and testes of $M$. Cavasius.

\section{Materials and Methods}

The experiments were conducted to accomplish the present investigation for a period of 4 months from July to October 2011 in the Department of Fisheries Management, Bangladesh Agricultural University, Mymensingh, Bangladesh. During the study periods, 50 no. of experiential fishes were collected at twenty days interval and brought to the laboratory to measure the total length, standard length and body weight and gonad weight were noted with the help of a sensitive portable electronic balance. After the dissection gonads were taken in vials filled with $10 \%$ formalin (at least 10 times the volume of the tissue) and kept at room temperature for further histology. The value of GSI was measured using the following formula.

$$
\text { GSI }=\frac{\text { Gonad Weight }(\mathrm{gm}) \times 100}{\text { Total Body Weight }}
$$

\section{Histology of Gonads}

Just before the study gametogenesis, firstly the preserved gonads were taken out from the vials (kept in fixatives) and put into cassette. Preferably, one testis and one ovary were put into a cassette. Then the standard methods were carried followed by clearing, infiltration, and embedding, sectioning, staining, mounting and finally microscopic observation. These steps mentioned below:

\section{Dehydration}

The fixed gonads samples were kept into the cassette and passed through a five stapes graded alcohol series and after that kept into glass jars. The samples that kept in $10 \%$ formalin fixative were started dehydration from $70 \%$ ethyl alcohol and the samples that preserved in $100 \%$ ethyl alcohol started dehydration from $100 \%$ ethyl alcohol. The dehydration schedule is given below.

\section{Clearing \& infiltration}

Dehydrated gonads were cleared by using Chloroform twice successively for 2-3 hours to remove traces of alcohol in order to have consistent paraffin blocks. In each cassette there were already single sample of both testes and ovary. From Chloroform, the cassettes with samples were put in automatic tissue processor.

\section{Embedding}

After infiltration, the cassettes were taken out one by one, being opened, settling the two samples in the middle of the cassette and filled with melted paraffin from wax dispenser. Then a steel cover was placed on each cassette. Then the cassettes were allowed to cool in room temperature. After cooling the cassettes were put in dip freezer for few minutes which allowed easy removal of steel plates from the cassettes and also smooth sectioning.

\section{Trimming}

Trimming is a process in which the undesirable wax layers of the embedded blocks are trimmed by knife to obtain suitable blocks. Trimming was done by using old microtome blades. Trimming allowed easy sectioning. In this step both side trimming and surface trimming were conducted.

\section{Sectioning}

Paraffin embedded blocks was cut by microtome knife in microtome machine at $5 \mu \mathrm{m}$ size. The sections were placed on lower part of a glass slide previously tagged and filled with water drops. The sections were kept overnight at room temperature for proper drying. Then the sections were stained routinely with haematoxyline and eosin as per the schedule given below.

\section{Staining}

Staining is a process by which samples are stained with various dyes and staining materials so that their components are visible under microscope. Standard methods are used for staining.

\section{Mounting}

In this process the tissue sections on the slide are covered with a cover slip DPX was used for mounting a mounting agent. A jot of DPX was put on each slide followed by attachment of cover slip $(22 \mathrm{~mm} \times 22 \mathrm{~mm})$. After mounting the slides were put for overnight in room temperature.

\section{Microscopic examination of the gonad tissue sections}

After mounting the slides were observed under a microscope which was connected to computer with a viewer (Magnus viewer). The viewer was also equipped with a camera. By the help of this mechanism numerous photographs were snapped at different magnifications.

\section{Statistical analysis of data}

The mean value and were calculated with the help of "Excel" computer based software. Photographs were taken under a digital camera (Model no. SONY DSC-W220) and microscope (Model no. Olympus- CX41).

\section{Result}

\section{Ganado-somatic index (GSI) of M. cavasius}

The GSI values of female $M$. cavasius ranged from 18.66 to 0.19 during the study period where the highest GSI value 24.54 was 
observed in late July. Otherwise the GSI values of male $M$. cavasius ranged from 3.41 to 0.05 during the study period where the highest GSI value 3.41 was observed in Early July. Monthly mean GSI values of female and male $M$. cavasius were presented in (Figure 1 \& 2) respectively.

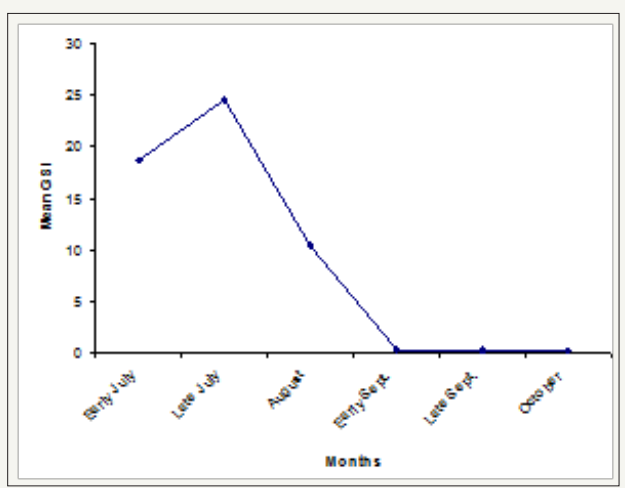

Figure1: Monthly mean GSI values of female Mystus cavasius.

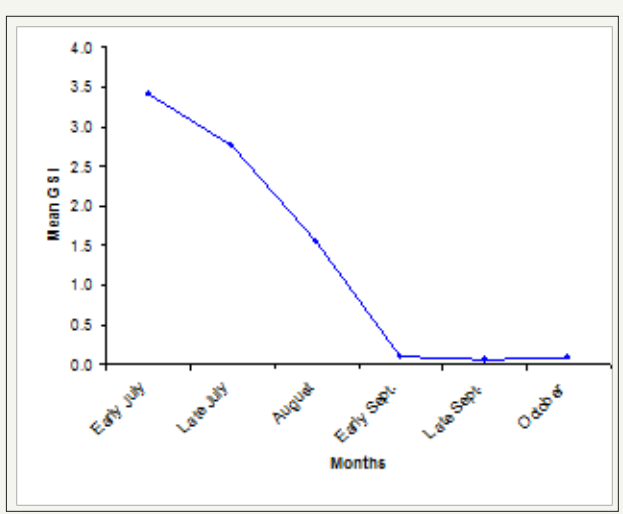

Figure 2: Monthly mean GSI values of male Mystus cavasius.

\section{Histological study of gametogenesis}

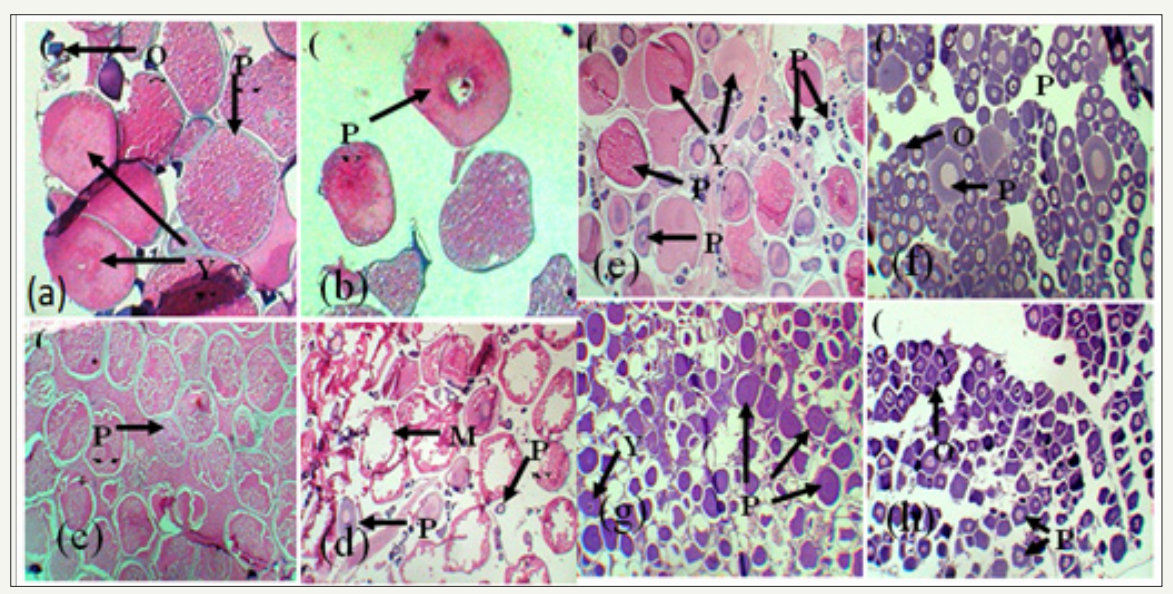

Figure 3: Haematoxylin-eosin (H-E) stained sections of Mystus cavasiusovary (at 4×) sampled in(a-b)Early July:(a) OG, Oogonia; YV, yolk vesicle and PM, pre-mature stage;(b)PVO, previtellogenic oocyte; (c-d) Late July: (c) PM, Premature; (d) M, mature; PVO, previtellogenic oocyte and PNO, Perinucleolar oocyte and(10x)sampled in (e)August: PNO, perinucleolar oocyte; PVO, previtellogenic oocyte; YG, yolk granule and PM, premature; (f)Early September: OG, oogonia; PNO, perinucleolar oocyte and PVO, previtellogenic oocyte; (g)Late September: PNO, perinucleolar oocyte; YV, yolk vesicle; (h)October: OG, oogonia; PNO, perinucleolar oocyte 
Ovarian stages of M. Cavasius: After microscopic observation of the ovary sections the following stages were observed and recorded month-wise in ovary: In Early July, Oogonia, (OG); previtellogenic oocyte, (PVO); yolk vesicle,(YV); and premature, (PM) stages were observed (Figure 3a \& 3b), In Late July, Perinucleolar oocyte,(PNO); previtellogenic oocyte, (PVO); premature,(PM)and mature, (M) stages were observed. PM and M stages were highest in number (Figure 3c \& 3d), In August, Perinucleolar oocyte, (PNO); previtellogenic oocyte, (PVO); previtellogenic oocyte, (YG) and premature, (PM) stages were observed. PVO and PNO stages were highest in number (Figure 3e), In Early September, OG, Perinucleolar oocyte, (PNO) and previtellogenic oocyte, (PVO) stages were observed. PNO stages were highest in number (Figure 3f), In late September, yolk vesicle, (YV) and Perinucleolar oocyte, (PNO) stages were observed.PNO stages were highest in number (Figure 3g), In October, Oogonia, (OG) and Perinucleolar oocyte, (PNO) stages were observed highest in number (Figure 3h).
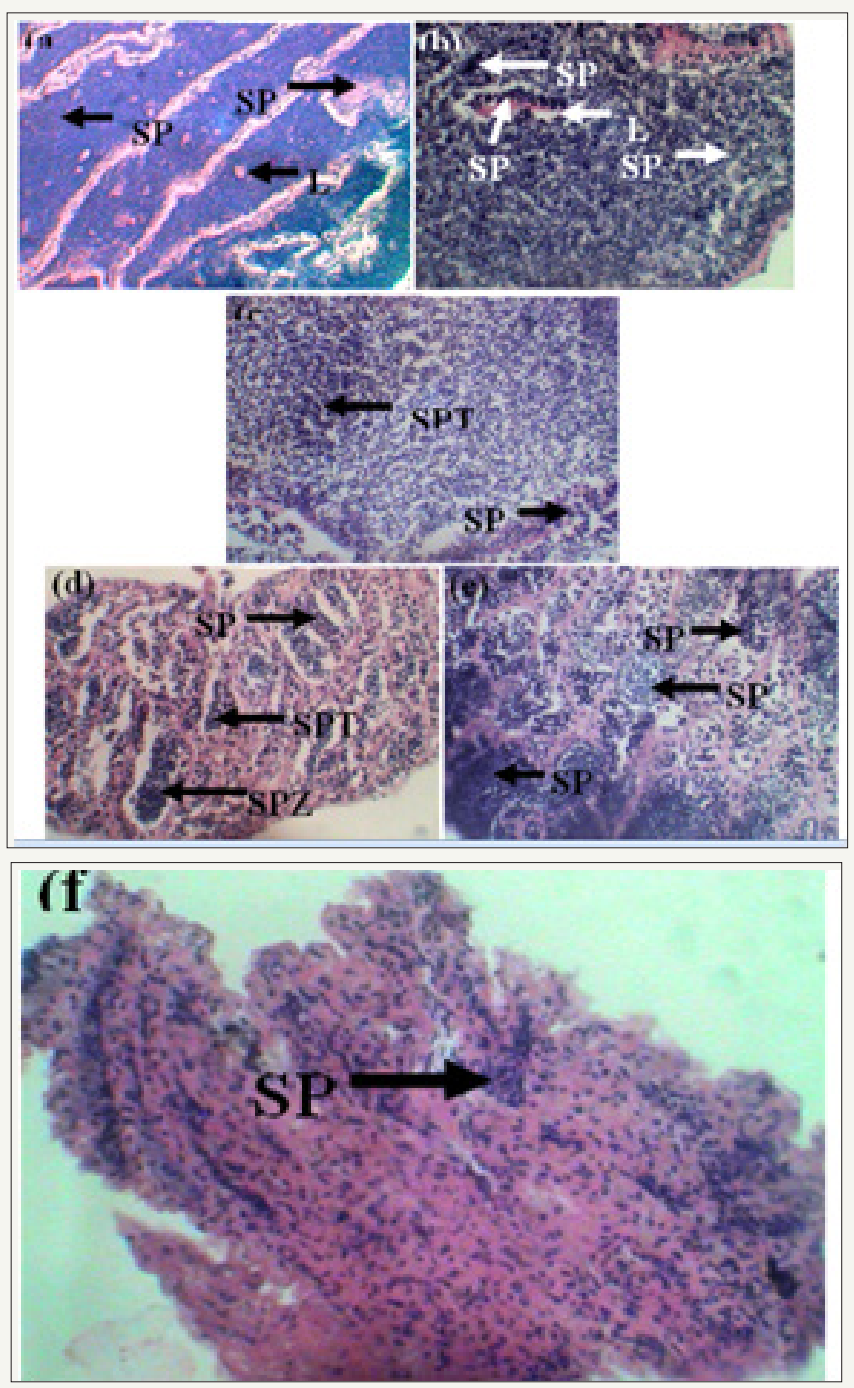

Figure 4: Haematoxylin-eosin (H-E) stained sections of Mystus cavasius testes (at 40x) sampled in (a) Early July: SPT, spermatids; SPZ, spermamatozoa and LU, lumen of tubules and (b) Late July: SPC, spermatocytes; SPT, spermatids; SPZ, spermatozoa and LU, empty lumen of tubules. (c)August: SPC, spermatocytes; SPT, spermatids and spermatozoa, (d) Early September: SPC, spermatocytes; SPT, spermatids SPZ, spermamatozoa and (e) Late September: SPC, spermatocytes; SPT, spermatids and SPZ, spermamatozoa. (f)October: SPC, spermatocytes.

Testicular germ cells of M. Cavasius: The following testicular germ cells were observed recorded month-wise in testes $M$. Cavasius: In Early July, Spermatids, (SPT); Spermatozoa, (SPZ) and empty lumen of tubules (LU) were observed. SPZ were highest in number (Figure 4a), In Late July, Spermatocytes, (SPC); Spermatids, (SPT); Spermatozoa, (SPZ) and LU were observed. SPT were highest in number (Figure 4b), In August, Spermatocytes, (SPC); Spermatids,
(SPT) and Spermatozoa, (SPZ) were observed. SPT and SPZ were highest in number (Figure 4c), In Early September, Spermatocytes, (SPC); Spermatids, (SPT) and Spermatozoa, (SPZ) were observed. SPC were highest in number (Figure 4a), In Late September, Spermatocytes, (SPC); Spermatids, (SPT) and Spermatozoa, (SPZ) were observed. SPC and SPT highest in number (Figure $4 \mathrm{~b}$ ) and In October, Spermatocytes, (SPC) were highest in number (Figure 4c). 


\section{Discussion}

Mystus cavasius is one of the important small indigenous fishes in Bangladesh. Proper management of this fish is related to availability of information on biology, reproductive biology in particular. The maturity, spawning season and gonadal development of this fish have not been well studied yet. Therefore, the main objectives of the current study on reproductive biology study of M. cavasius were to identify the gonado-somatic index (GSI) and gonadal development of ovary and testes. Information on gonadal development and the spawning season of a species are expected to makes subsequent studies easier to trial captive maturity and reproduction.

\section{The GSI}

The GSI value of M. cavasius showed a clear pattern for spawning season during the study period. The highest mean GSI for male M. cavasius was 3.41 in early July and the lowest was 0.05 in late September and for female it was 24.54 in late July and the lowest was 0.19 in October. The highest GSI value of testis in early July and that of ovary in late July indicates that male matures earlier than female. Saha et al. [8] found the Gonado-somatic index in case of Catfish (Heteropneustes fossilis)value for male was found highest (0.847) in early June and lowest (0.169) in early March, and for female it was highest (14.457) in early June and lowest (4.286) in early March.

The GSI increases with the maturation of fish, being maximum during the period of peak maturity and declining abruptly thereafter, when the fish become spent [9]. In this present findings it is show that GSI value of $M$. cavasius is highest in Peak season after breeding it become reduce. So, we can say present finding is more similar with Le Cren [9] \& Saha et al. [8]. Faruq [10] described that four catfish species viz. M. cavasius, $M$. vittatus, $H$. fossilis, and Clarias batrachus breeds from June and July. Banu [11] determined that the peak spawning of M. tengra occurs in July; supporting the present study. In a similar study on Ompok pabo from the Sylhet basin, Alam [12] recorded that the highest GSI for male was $1.006 \pm 0.326$ in June and the lowest was $0.614 \pm 0.053$ in April and for female it was highest in June 14.45 \pm 2.37 and lowest in April 10.51 \pm 0.82 . Akhter [13] found similar results in Pangasius pangasius, showing that the highest GSI of female collected from Meghna River during May to October, 2011 was 7.55 in June and for male it was 1.19 in June. Motin [14] studied GSI of post spowning pabo catfish (Ompok pabo) and founded the highest average GSI value in female was 4.06 in September and the lowest was 1.55 in November. For male, the highest was 0.76 in December and the lowest was 0.43 in October. High GSI and appearance of mature oocytes appeared in July indicated peak breeding season of $M$. cavasius to be in July. There were presences of mature germ cells in the testicular lumen almost throughout the breeding season. The findings from GSI value and ovarian and testicular stages concludes that M. cavasius from the Mymensingh region (part of the Sylhet basin) attains peak reproductive maturity in late July that is why we can present investigation is more or less similar to the above findings.

\section{Histological study of gonads}

Ovarian stages: In this study, oocytes maturation stages were classified into oogonia (OG), perinucleolar oocytes (PNO), previtellogenic oocytes (PVO), yolk vesicle stage (YV), yolk granule stage (YG), premature (PM) and mature (M) stage. In fish ovary, the $\mathrm{PM}$ and $\mathrm{M}$ stages are generally observed at the most advanced stage of ovary when the fishes are ready for spawning and when mean GSI values are comparatively high. Histological study of M. cavasius ovary observed PM and M oocytes from early July to August samples - indicating spawning season of this fish from 'haor' waters. The occurrence of M stage together with highest GSI value in late July indicates peak breeding season of this fish in late July. The ovaries contained developing oocytes (OG, PVO and PNO) in post-monsoon September samples, indicating spent phase of ovary.

Similar studies with $M$. vittatus from a perennial water body of Bangladesh, Ziki [6] reported that the spawning season of $M$. vittatus were from February to July. In case of 0 . pabo from the Sylhet basin, Alam [12] identified EP, LP, YV, EYG, LYG, MN, PM and M stages in ovary studied during April to July. Akter [15] observed six stages of gradually maturing oocytes, viz., undeveloped oocyte (UO), PNO, PVO, vitellotenic oocyte at vesicle breakdown stages (VO-vb), vitellotenic oocyte at vesicle hydration stages (VO-h) in captive catfish P. pangasius ovary sampled from during May to October.

Study of reproduction cycle of giant river catfish Sperata seenghala from the Sylhet basin during May to August observed seven stages of oocytes, viz. PVO, YV, EYG, LYG, PM and M stage; similar to the present study [13]. Ulka [16] studied the histology of three kinds of koi (Thai, native, hybrid koi) and observied Seven oocyte maturation stages viz. early perinucleolus (EP), late perinucleolus (LP), yolk vesicle (YV), early yolk granule (EYG), late yolk granule (LYG), premature (PM) and maturature (M) stages were observed in ovary of native, Thai and hybrid koi. It was observed that oocytes did not develop synchronously and oocyte at various maturation stages were observed in paired ovaries in native, Thai and hybrid koi. Motin [14] studied histological study of gametogenesis in endangered pabo catfish (Ompok pabo) from the Sylhet basin in the north-east Bangladesh and observed four ovarian stages such as oogonia, perinuclear oocytes, previtellogenic oocytes and yolk granule stages and also observed that oocytes did not develop synchronously.

From the histological study of ovary at successive months, it was observed that oocytes did not develop synchronously and oocytes at various maturation stages were observed in paired ovaries in M. Cavasius. In the ovaries of M. Cavasius, collected during July to October, the following oocytes were observed: oogonia (OG), perinucleolar oocytes (PNO), previtellogenic oocytes (PVO), yolk vesicle (YV), yolk granule (YG), premature (PM) and mature (M) stage. In this study, the mature stages of oocytes (PM and M) were observed from early July to August samples of ovary. The ovaries contained developing oocytes (OG, PVO and PNO) in the September samples which were mostly spent. 
Testicular stages: The testicular germ cell stages observed were spermatocytes (SPC), spermatids (SPT), spermatozoa (SPZ) and also empty lumen of tubules (LU). From the histological study of testes it was found that testes of M. cavasius were rich in SPT and SPZ during July to August, although there were evidences of SPC in late July and August samples, but were very few. This finding indicates breeding season of male of $M$. cavasius and is indicative of the fact that the male fishes get mature and ready to spawn during the entire breeding season. After peak breeding season, SPZ were not abundant, SPC and SPT being higher in number.

Again, high abundance of early stage germ cells (mainly SPC) in the September and October samples indicate post-spawning spent phase of this fish. In a similar study, Alam [12] observed large amount of SPT, SPZ and small amount of SPC in testis of 0. pabo during April to July. In Heteropneustes fossilis, Saha et al. [8] described that SPT were in high abundance during early April to early May and also SPZ were prominently visible during early June. On the other hand Motin [14] studied on gametogenesis of O. pabo identified SPC, SPT, SPZ and empty LU during the post-spawning season testes. The results of the present experiment indicated that the GSI of M. cavasius is highest in Late July and most oocytes with $\mathrm{PM}$ and $\mathrm{M}$ stages were also observed in late July indicating its peak breeding season.

The present studies also indicate that mature germ cells were present in the testicular lumen almost throughout the breeding season. According to the above discussion, combining the findings from GSI value and ovarian and testicular stages, it can be concluded that $M$. cavasius from the Mymensingh region (part of the Sylhet basin) attains peak reproductive maturity in the month of July, particularly during the later part of the month. From the histological study of testes of M. Cavasius, high proportions of mature germ cells (SPT and SPZ) were observed from July to August samples of testes, although there were evidences of SPC, but were very few. High abundance of early stage germ cells (mainly SPC) were observed in the September and October samples indicate spent phase of this fish.

\section{Conclusion}

In Bangladesh, there is limited knowledge about stocks, habitats, behaviour, reproduction, spawning etc. of important fish species required for their sustainability management in the nature. Towards this venture the preliminary information generated on the breeding biology and subsequent success in induced breeding trials can serve as the base for further research on $M$. cavasius with an aim of establishing the package of induced breeding and to management and conserve from the threatened condition. However, for a better understanding of reproductive biology of any species, it is important to study the ovary and testes histologically and most importantly the oocyte development process. This study provides for the first elaborate information on oogenesis and spermatogenesis of M. cavasius from the Sylhet 'haor' basin in the Northeaster Bangladesh.

\section{References}

1. Khan MA, Rashid H, Fatema MK, Sukhan ZP, Hossain MAR, et al. (2016) First Record of Seed Production of Swamp Mud Eel (Monopterus cuchia) in Captivity by Environment Manipulation. Fisheries and Aquaculture News, Bangladesh 4: 24-27.

2. Siddiquee A, Rashid H, Islam MA, Ahmed KKU, Shahjahan M (2015) Reproductive biology of great snakehead channamarulius from sylhet basin in the north east bangladesh. Journal of Fisheries and Aquatic Science 10(4): 294-299.

3. Rashid H, Matsuyama M, Yamaguchi A (2011) Gonadal sex differentiation and development in Japanese tiger puffer: role of aromatase isoforms. LAP LAMBERT Academic Publishing GmbH \& Co KG, Germany, p. 116.

4. Rahman AKA (2005) Freshwater Fishes of Bangladesh, (2 ${ }^{\text {nd }}$ edn), Zoological Society of Bangladesh, Dhaka, Bangladesh, p. 394.

5. IUCN Bangladesh (2015) Red List of Bangladesh Freshwater Fishes. IUCN, International Union for Conservation of Nature, Dhaka, Bangladesh 5: 360 .

6. Ziki TB (2006) Reproductive biology of Mystas vittatus of a perennial water body in Bangladesh. M.S. thesis, Department of Fisheries Management, Faculty of Fisheries, Bangladesh Agricultural University, Mymensingh, pp. 21-50.

7. Islam MK, Das M (2006) Fecundity of gulsa Mystus cavasius from the Bramaputra and Kongsa rivers. J Bangladesh Agril Univ 4(2): 347-355.

8. Saha SK, Ali MH, Rashid H (2014) Gametogenesis in Captive Stinging Catfish (Heteropneustes fossilis) During Spawning Season. Proceedings of $5^{\text {th }}$ International Conference on Environmental Aspects of Bangladesh (ICEAB 2014), pp.126-128.

9. Le Cren ED (1951) The Length-weight relationship and seasonal cycle in gonad weight and condition in perch. J Amin Ecol 20(2): 201-219.

10. Faruq MA (1995) Studies on the fecundity of Heteropneustes fossil is, Clarias batrachus, Mystus cavasius and Mystus vittatus. Thesis MS Department Aquaculture and Management, Bangladesh Agricultural University, Mymensingh, p. 66.

11. Banu N, Ali S, Alam SMN (1992) Studies on the fecundity of Mystus tengara of Agargaon region. Dhaka, Uni J Biol Sci 1: 49-51.

12. Alam MS (2009) Length-weight relationship and reproductive physiology of three endangered pabda fishes from Sylhet basin. Thesis MS, Department of Fisheries Management, Bangladesh Agricultural University, Mymensingh, Bangladesh, pp. 6-19.

13. Akhter T (2011) Reproductive cycle of giant river catfish Sperata seenghala from the Sylhet basin. Thesis MS, Department of Fisheries Management, Bangladesh Agricultural University, Mymensingh, Bangladesh, pp. 31-34.

14. Motin MA, Rashid H, Maya M, Sarkar MRU (2013) Histological study of gametogenesis in endangered pabo catfish (Ompok pabo) from the Sylhet basin in the north-east Bangladesh. $5^{\text {th }}$ International Conference on Environmental Aspects of Bangladesh.

15. Akter S (2011) Histological study of gametogenesis in captive pangasius catfish Pangasius pangasius. Thesis MS Department of Fisheries Management, Bangladesh Agricultural University, Mymensingh, Bangladesh, pp. 35-40.

16. Ulka SB (2011) Study to the improved management of koi (Anabas testudineus) hatchery, the peak breeding season and gonadal maturity stages of native, Thai, and hybrid (Thai? $\times$ native?). In: koi MS Thesis (Ed.), Department of Fisheries Management, Bangladesh Agricultural University, Mymensingh, Bangladesh. 
Creative Commons Attribution 4.0 International License

For possible submissions Click Here

\section{Examines in Marine Biology \& Oceanography}

\section{Benefits of Publishing with us}

- High-level peer review and editorial services

- Freely accessible online immediately upon publication

- Authors retain the copyright to their work

- Licensing it under a Creative Commons license

- Visibility through different online platforms 